\title{
Pragmatic Aspect of Phraseological Units in the English Language
}

\author{
Angelika Fedoryuk ${ }^{1, *}$ \\ ${ }^{1}$ Irkutsk State University, 664003, Irkutsk, Russia
}

\begin{abstract}
The paper deals with the phraseological intensifiers considered as means of categorization of language intensity which is defined as the amount of illocutionary force that the utterance has, degree of strength of verbal expression of the speakers' intentionality. The paper reveals the pragmatic peculiarities of the phraseological intensifiers in conversation in which they serve as an instrument used by individuals in order to attain certain communicative goals, to convey the speaker pragmatic meaning. In argumentation, which is believed to be a macro speech act, having the illocutionary point to convince a reasonable critic of the acceptability of the standpoint and to resolve differences of opinion, the phraseological intensifier is used to increase the illocutionary force of the argument for and against the expressed standpoint.
\end{abstract}

\section{Introduction}

Over the years one persistent research area has been on the effects of intense language. In the review of important language variables the scholars J.J. Bradac, J.W. Bowers and J.A. Courtright [1] reported that three variations in language have been demonstrated to influence receivers' responses; among these is language intensity. Studies have shown the positive effects of language intensity on attitude change in communication. Early research conducted on language intensity was based around the widely accepted definition offered by John Waite Bowers, he defined language intensity as «the quality of language which indicates the degree to which the speaker's attitude toward a concept deviates from neutrality» [2]. Similarly, Burgoon, Jones and Stewart defined language intensity as «language indicating degree and direction of distance from neutrality» [3].

In terms of language pragmatics on which our research is based by intensity we mean a feature of the language conveyed on the one hand through the properties of illocutionary force of the utterance and on the other hand through the speaker's intentionality. Correspondingly language intensity in the paper is defined as the amount of illocutionary force that the utterance has, degree of strength of verbal expression of the speakers' intentionality. The subject matter under consideration is the phraseological means of categorization of language intensity, namely a phraseological intensifier.

\section{Phraseological intensifier as a means of categorization of language intensity}

One of the leading authority on problems of English phraseology in Russia professor A.V. Koonin defined phraseological intensifiers as phraseological units with completely transferred meanings of their constituents [4]. He stated that the constituents of the phraseological intensifier had changed their current or literal meanings completely and as a result the phraseological unit has acquired the intensifying meaning. Here are some examples of phraseological intensifiers used in English: like the devil, like hell - with great speed, force or energy; like a short - very fast; like fury - with great energy or effort; like anything- very much, hard, or strongly; like the dickens - furiously; very much; like one o'clock, like lightning - very quickly; like a bat out of hell - with great speed and force; like crazy, like mad - furiously; very much; fast or actively; like a house on fire, like a house afire - rapidly and with force; as hell - recklessly, exceedingly (Oxford Dictionary of Idioms).

Being one of the means of categorization of language intensity the phraseological intensifiers are considered to be the only class of phraseological units in the phraseological taxonomy that is closer to the semiotic concept of a sign, are presented as signs of secondary predication, which are used to intensify qualities, actions, states, conveyed by the lexical units, but in the discourse they are presented as signs of illocution, signs that are used (1) to boost the speaker's illocutionary force and especially to maximize the dramatic effect in communication and (2) to elicit attention from the hearer in conversation and, under certain circumstances, (3) to establish rapport between interlocutors.

\section{Phraseological intensifier and speaker pragmatic meaning}

Our attempt at analyzing the pragmatic and functional peculiarities of the phraseological intensifier in the discourse could be classified on the one hand as functional which views discourse as language in use, the way in

\footnotetext{
* Corresponding author: Fedoryuk@rambler.ru
} 
which the language is used and which presupposes that speakers use phraseological intensifiers in such a way as to communicate messages that would manage to change the hearers mentally or emotionally, thus modifying their knowledge, convictions or feelings and on the other hand as a pragmatic, which focuses on the speaker pragmatic meaning at the level of utterances or speech acts situated in a discourse. Correspondingly by the discourse we mean the sequence of speech acts, each speech act having the propositional content and the illocutionary force, defined by J.R. Searle and D. Vanderveken as the degree of the speaker's intention in producing that utterance [5].

When analyzing the pragmatic peculiarities of the phraseological intensifier in the discourse of casual conversation we have found out that it serves as an instrument used by individuals in order to attain certain communicative goals, or in other words it conveys the speaker pragmatic meaning. According to D. Schiffrin, pragmatic meaning concerns the speaker's communicative intention, the direct (not implied) «message the speaker intends to convey in uttering the sentence» [6].

The speaker's intention in producing the utterance is defined by J. Searle and D. Vanderveken as the illocutionary force of a speech act. In the discourse the phraseological intensifiers are the basic pragmatic markers or signals of the illocutionary force. They contribute to the establishing and developing the illocutionary force of the speech acts, comprising the discourse, in other words they function as a means of illocutionary semantics of the discourse.

\subsection{Phraseological intensifier as a means of establishing the illocutionary force of the discourse}

It is important to notice that the phraseological intensifiers are the signals of the illocutionary force of the utterance only in the conditions of the dialogue complementation, by which we mean the speech action aimed at hearer's structural and semantic completing the speaker's initial phrase. Let's consider the example in which the phraseological intensifier establishes the illocutionary force of an assertion, i.e. it commits the speaker to something being the case,

1. «Does your tooth hurt?»

"Like the dickens».

"So does mine. Coo!»

«Coo here too» (COCA).

The question «Does your tooth hurt?» in the example under consideration is not an utterance yet, it is just a stimulus going from the speaker and making the hearer produce the utterance. The reply, consisting of the phraseological intensifier «Like the dickens» which means «furiously; very much» doesn't have the semantic independence apart from the question. The illocutionary act reply is very tightly constrained by the question that precedes it; only being mutually complementary the question becomes the utterance with the proposition of inquiry about some information and the answer obtains the illocutionary meaning of assertion. Let's consider the second example:
2. "... and suppose I do Mary and I get permission to broaden the scope of the research, would you come to work with me?»

«Like a shot», she said. "Equal pay for equal work» (COCA).

In accordance with J. Searle's theory [5] every complete sentence, even a one-word sentence has some indicator of illocutionary force; in the example under consideration the speech act, consisting of the phraseological intensifier «like a shot» (very fast), has the illocutionary force of a promise, i.e. it commits the speaker to doing something in the future, namely, equal work for equal pay. As we can see the reply, containing the phraseological intensifier, is very tightly constrained by the speech act with the illocutionary force of request that precedes it as in question and answer sequences shown in the casual conversation in the first example. In both examples the phraseological intensifiers establish the illocutionary force of the utterances, they elicit attention from the hearer in conversation and establish rapport between interlocutors, i.e. they convey the speaker pragmatic meaning.

\subsection{Phraseological intensifier as a means of developing the illocutionary force of the discourse}

Now let's consider the contribution of the phraseological intensifier to the developing the illocutionary force of the discourse. The contribution of the phraseological intensifier to the developing the illocutionary force of the discourse consists in boosting the illocutionary force of the utterances, comprising the discourse. According to J.R. Searle and D. Vanderveken each illocutionary force has seven interrelated components: (1) illocutionary point or purpose, which is by far the most important component; 2 . degree of strength of the illocutionary point; (3) mode of achievement of that point, (4) propositional content conditions, (5) preparatory conditions, (6) sincerity conditions, (7) degree of strength of the sincerity conditions [5]. Two components of the illocutionary force are of interest for our research, namely the degree of strength of the illocutionary point and the degree of strength of the sincerity conditions, so as the contribution of the phraseological intensifier to the intensifying these two components is significant.

The illocutionary point constitutes the most important and basic element of the illocutionary force, it determines the objective, the intention of the utterance. Most illocutionary points can be achieved with greater or lesser degrees of strength in the world of utterance. It is the degree of strength of the illocutionary point that enables to differentiate between two utterances of the same illocutionary type. So the assertive illocutionary point that commits the speaker to the truth of the expressed proposition can be achieved by means of declaration, statement, prediction, supposition. The speaker, who asserts, declares, predicts and supposes that something is the case, expresses the propositional content in varying degrees of strength. If the speaker supposes that something is the case the degree of strength of representation that it is the case less than if the speaker asserts that it is the case. 
According to the foundations of illocutionary logic we have: degree (//to assert//)> degree (// to suppose//). Consequently «to assert» is more intense than «to suppose»,

e.g.: Old Sally's ankles kept bending in till they were practically on the ice. They not only looked stupid, but they probably hurt like hell too. She was killing herself. It was brutal. I really felt sorry for her (J.D. Salinger «The Catcher in the Rye»).

«To assert» is more intense than «to suppose», that's why in order to achieve the illocutionary point of supposition, expressed by an adverb "probably» which is generally used «to say that something is likely to be true in this particular case that the girl's ankles are likely to hurt her, the speaker uses the phraseological intensifier «like hell» (with great force or energy) to make his utterance with the illocutionary point of supposition count as an assertion and consequently to make it sound convincingly. According to D. Vanderveken's point of view, supposition requires some evidence [7]. In the utterances under consideration the speaker gives some evidence of the fact that the girl suffered ankles' ache performing the following speech act «.... ankles kept bending in till they were on the ice». Besides, the ache was strong, the utterances: «She was killing herself» and «It was brutal» prove it.

J. Searle stated that in the performance of each illocutionary act with a propositional content, we express a certain Intentional state [8]. The speaker in the example considered above performs the speech act «I really felt sorry for her» to express the intentional state of regret directed at the girl. Now let's compare two utterances performed by the speaker. The speech acts have the assertive illocutionary points expressed in varying degrees of strength:

"I think you are guilty», she said quietly. «I think you are guilty as hell» (A. Drury «Decision»).

As we can see the utterances have the same propositional content «I think you are guilty» and the assertive illocutionary forces (the verb «to think» indicates them). Both illocutionary forces have the same point but differ in degrees of strength, correspondingly the illocutionary point in the second utterance is expressed with the greater degree of strength than it is expressed in the first utterance. The speaker uses the phraseological intensifier «as hell» (recklessly, exceedingly) to increase the illocutionary force and to convince the hearer of the truth of the expressed propositional content, namely of the hearer's guilt. The examples considered above demonstrated the increasing the assertive illocutionary force of the utterances by means of the phraseological intensifiers.

\subsection{Phraseological intensifier in argumentation}

Being the means of convincing the hearer of the truth of the expressed propositional content the phraseological intensifiers are used in the argumentative discourse, defined by F.H. Eemeren, R. van, Grootendorst as a verbal activity of reason aimed at increasing (or decreasing) the acceptability of a controversial standpoint for the listener or reader, by putting forward a constellation of propositions intended to justify (or refute) the standpoint
[9]. In terms of contemporary research of the pragmatic approach to argumentation, by argumentation we mean a macro speech act, having the illocutionary point to convince a reasonable critic of the acceptability of the standpoint and to resolve differences of opinion. Structurally each macro speech act of argumentation consists of the speech act presenting the standpoint and the speech acts presenting arguments for or against the standpoint. Both types of speech acts have the propositional contents and the illocutionary forces.

Our research has revealed that in the macro speech act of argumentation the phraseological intensifier is used to increase the illocutionary force of the argument for and against the expressed standpoint. Let's consider the example of the argumentative discourse, taken from the play «Penelope» by W.S. Maugham in which the phraseological intensifiers serve as a means of increasing the illocutionary force of the arguments that were put forward to defend the standpoint.

[Dickie comes in with a little medicine glass, filled with a milky fluid.]

Dickie (D): Here it is. (Take it $\rightarrow$ the standpoint is expressed implicitly)

Penelope (P): Oh, no, Dickie, I'd much rather not.

D.: Don't be silly, darling. This'll pull you together like anything. $\rightarrow$ an argument

P: No, I think I'd rather lie down on this sofa.

[She lies down on a sofa.]

D: Let's put this rug over your feet. There. Now take this medicine. ... There ...

P: Oh, no, Dickie. I'll take it after you've gone. I really will. I promise you I'll take it.

$D$ : Why on earth can't you take it now?

P: Well, I hate making faces before you.

D: But I've often seen you make faces.

$P$ : Yes, at you. That's quite a different thing.

D: Now take it like a good girl. $\rightarrow$ a standpoint

It'll make you feel better like one o'clock. $\rightarrow$ an argument

$P$ : After you've gone.

D: [With great determination.] I'm not going to stir from this room till you've taken it.

P: [Resigned.] Give it me. Hold my nose, Dickie. [She swallows it and makes a face.] Oh, I wish I'd never married you, Dickie (W.S. Maugham "Penelope").

The macro proposition of the macro speech act of argumentation is as follows «Dickie convinces his wife Penelope to take the medicine». While convincing his wife to take the medicine the speaker tries to be persistent (he puts forward his standpoint three times) and performs several speech acts with assertive illocutionary points to justify the standpoint, e.g. «This'll pull you together like anything» and «It'll make you feel better like one o'clock». The phraseological intensifiers «like anything» (very much, hard, or strongly); and «like one o'clock» (very quickly) increase the illocutionary force of argumentation, hence make the arguments reasonable and the macro speech act successful. The speaker manages to convince his wife to take the medicine (the sentence: «She swallows it and makes a face» proves it). It follows that in argumentation the speaker's intense language enhances credibility and promotes arguments acceptance. We have considered the assertive illocutionary speech acts served as 
reasonable arguments in the macro speech act of argumentation.

The directive speech acts are attempts (expressed in varying degrees) by the speaker to get the hearer to do something [5]. They may be very modest attempts as in the case of request, or they may be very fierce attempts as in the case of orders or commands or as in the case of the intense expression of the illocutionary point of request, represented in the following example:

«Would it be too much to ask you to fly like a bat out of hell? I've a date», Biff said. Mr. Scarborough assured him that he would be back in twenty minutes, if not sooner, and his promise was fulfilled (COCA).

As we can see the hearer responded to the intense request and the speech act with illocutionary force of request was successful due to the use of the phraseological intensifier «like a bat out of hell» (with great speed and force). In the discourse the phraseological intensifier contributes not only to the developing but also to accumulating the illocutionary force of the discourse, it maximizes the dramatic effect in communication.

1. «So», she said, «tell me about Jane».

«Janie», he said, eyes and voice suddenly filling with pride, «is quite a girl. She's almost fifteen - tall - blonde dark-eyed, which makes for a combination - everything in the right proportions and getting more so - charming lovable - extremely intelligent - quick-witted - just a hell of a bright kid» (A. Drury «Decision»).

2. «They beat you up. You really did hurt like hell», she said, a worried, sympathetic voice behind him. He started to roll back and she said sharply, «Don't move if it hurts you!» (A. Drury «Decision»).

The examples presented above are sequences of the assertive illocutionary acts, used by the speakers to express the intentional states of pride directed at the speaker's daughter in the first example and the intentional state of sympathy directed at the hurt man in the second example. As far as the intensity of dramatic effect caused by the speakers' intentional and emotional experiences in both examples is growing the degree of strength of the illocutionary point is increasing gradually. The increasing of the degree of strength is realized by means of intensifiers, at first by means of the lexical intensifiers «quite»(1) and «really» (2), then by the adverbial intensifier «extremely» (1) and emphatic «did» (2) and finally by means of phraseological intensifiers «a hell of» (1) and «like hell» (2). The phraseological intensifiers are used by the speakers at the moment of the emotional and intentional culmination.

\section{Phraseological intensifier speaker's Intentional state}

All examples that have been illustrated and considered before demonstrate the intensity of verbal expression of illocutionary point by means of phraseological intensifiers. In what follows we adopt Searle's statement that in the performance of each illocutionary act with a propositional content, we express a certain Intentional state and that intentional state is the sincerity condition of that type of speech act [8]. Just as the same illocutionary point can be achieved with different degrees of strength, so the same sincerity conditions or intentional state can be expressed with different degrees of strength. The degree of strength of the sincerity conditions serves to indicate the different strengths with which the states of mental disposition are expressed.

It is important to note that all mental acts are characterized by consciousness and intentionality. Intentionality for H.G. Gadamer meant the correlation between the object of experience and its modes of givenness [10]. J. Searle defined Intentionality as the power of minds to be about, to represent, or to stand for, things, properties and states of affairs in the world [8]. Correspondingly this power can be strong or weak and according to H.G. Gadamer, is determined by the speaker's object of experience [10].

In order to reveal the correlation between the degree of strength of expression of the speaker's intentional state and the object of experience the linguistic experiment was carried out. The speakers were suggested two situations as objects of their experience. In the first situation the speaker had an experience of watching his/her friend behave in a situation when the person was angry (or frightened) for some reason. But that happened some time ago. The speaker's reminiscences have already faded and he/she is more of an observer.

In the second situation the speaker feels as if she/he was in that situation again. His/her friend's anger (or fear) still causes unpleasant reminiscences. The speaker is still sort of feel with his/her friend. These situations were described by four sets of sentences that had nearly identical meanings.

1. He was very angry. I was afraid he might lose selfcontrol.

2. He was angry as hell. I was afraid he might fly off the handle.

3. He was very frightened. I was afraid he might lose self-control.

4. He was frightened as hell. I was afraid he might collapse.

The participants of the experiment were asked which of the four sets of utterances they would rather assign to the first situation, and which ones to the second situation. The results of the experiment revealed that 21 participants of 30 had assigned the first and the third sets of utterances, containing the lexical intensifier «very» to situation 1 and the second and the fourth sets of utterances containing the phraseological intensifier «as hell» to situation 2. It leads us to the conclusion that when describing the faded unpleasant reminiscences caused by friend's anger and fear as an object of experience the speaker who is more of a reporter observer of the situation expresses the intentional state and uses the lexical intensifier «very». In case of describing the newly experienced unpleasant reminiscences the speaker uses the phraseological intensifier and the verbal phraseological intensifier «to fly off the handle» to express the intentional state. Hence, the newly experienced reminiscences are stronger than the faded reminiscences of an observer. Correspondingly the degree of strength with which the speaker, who experiences the situation again and expresses the intentional state, is greater than that in the situation with 
the speaker-observer. It follows that intensity is the degree of strength of expressing the speaker's intentional state.

To express a certain intentional state is to show in what way our mind is directed toward the world or in other words in what way our mind represents the world. There are three aspects which the intentional state can be directed at. They are: events, subjects and actions performed by them, objects and aspects assigned to them. In the speech acts presented below the phraseological intensifiers contribute to the intense expression of the speakers' intentional states: intentional state of love directed at the dog, e.g.: Both her father and her grandmother have died. Now even her dog, Stinky, has gone missing. Stinky is my dog. Once he was mine and Barnaby's, but now he's just mine. He's only a sweet shaggy old mutt but I love him like mad (COCA). Intentional state of wishing directed at the child, e.g. I wished like hell that it could have been my child (COCA). Intentional state of hope directed at the person, e.g.: «He's not worried about turning a huge profit. He's an absolute pillar of the community», another partner said. "For the city's sake, I hope like hell Moores gets it» (COCA).

\section{Conclusion}

In conclusion it should be stressed that messages employing phraseological intensifiers as a means of highintensity language consistently produced greater attitude change than similar messages using low-intensity language. It follows that in the discourse the phraseological intensifier is the very phraseological unit that has specific pragmatic orientation. Due to the intensity which is the leading seme in their semantics, they are widely used in different discourses to affect the interlocutors strongly.

\section{References}

1. J.J. Bradac, J.W. Bowers, J.A. Courtright, Three language variables in communication research: Intensity, immediacy, and diversity, Human Communication Research 5(3), 257-269 (1979)

2. J.W. Bowers, Language intensity, social introversion, and attitude change. Speech Monographs, 30 (4), 345352 (1963)

3. M. Burgoon, S.B. Jones, D, Stewart. Toward a message-centered theory or persuasion: Three empirical investigations of language intensity, Human Communication Research, 1, 240-256 (1975)

4. A.V. Kunin, A Course on modern English phraseology (Moscow, Vy'sshaya shkola, 1996) (in Russian)

5. J.R. Searle, D. Vanderveken, Foundations of Illocutionary Logic (Cambridge, Cambridge University Press, 1985)

6. D. Schiffrin, The Handbook of Discourse Analysis (Cambridge, Cambridge University Press, 2001)

7. D. Vanderveken Meaning and Speech Acts: Volume 2, Formal semantics of success and satisfaction (Cambridge, Cambridge University Press, 2009)

8. J.R. Searle Intentionality (Cambridge, Cambridge University Press, 1983)

9. F.H. Eemeren, van Grootendorst Fundamentals of Argumentation Theory. Handbook of Historical Backgrounds and Contemporary Developments (New Jersey, Lawrence Erlbaum Associate Publishers, 1996)

10. H.G. Gadamer, Truth and Method (New York, Routledge, 1988) 